http://dx.doi.org/10.1590/0102-4698125846

\title{
ARGUMENTAÇÃO SOBRE PROBLEMAS SOCIOAMBIENTAIS NO ENSINO DE BIOLOGIA
}

\author{
Dália Melissa Conrado* \\ Nei Freitas Nunes-Neto** \\ Charbel N. El-Hani ${ }^{* * *}$
}

RESUMO: O ensino de argumentação na educação científica, em todos os níveis, pode facilitar o processo de aprendizagem de ciência e contribuir para desenvolver o pensamento crítico e, ainda, melhorar a tomada de decisão pelo cidadão, entre outros benefícios. Partindo do pressuposto de que saber argumentar é fundamental nas atividades profissionais, discutimos o uso de questões sociocientíficas (QSCs) para promover habilidades argumentativas em um curso de extensão para acadêmicos da área de Ciências Biológicas. Usando modelos de análise de argumentação, avaliamos o conteúdo e a estrutura dos argumentos desenvolvidos pelos estudantes. Os resultados indicaram que as QSCs utilizadas favoreceram a aprendizagem e a prática das bases da argumentação. Contudo, houve limites quanto à qualidade dos argumentos. Isso indica a necessidade de maior investimento em estratégias de ensino que apliquem o conhecimento científico em problemas sociais, bem como da valorização do ensino explícito sobre bases de argumentação, ética e política no currículo de Biologia.

Palavras-Chave: Questões sociocientíficas. Argumentação. Modelo de Argumento de Toulmin. Agropecuária.

\footnotetext{
* Doutora em Ecologia pelo Programa de Pós-Graduação em Ecologia e Biomonitoramento da Universidade Federal da Bahia (UFBA). Doutoranda do Programa de Pós-Graduação em Ensino, Filosofia e História das Ciências na Universidade Federal da Bahia (UFBA). Pesquisadora do Laboratório de Ensino, Filosofia e História da Biologia (LEHFBio) . E-mail: dalia.ufba@gmail.com

* * Doutor em Ecologia pela Universidade Federal da Bahia (UFBA). Professor Adjunto do Instituto de Biologia da Universidade Federal da Bahia (UFBA). Professor do corpo permanente do Programa de Pós-Graduação em Ensino, História e Filosofia das Ciências da Universidade Federal da Bahia (UFBA). Coordenador do Laboratório de Ensino, História e Filosofia da Biologia (LEHFBio). E-mail: nunesneto@gmail.com *** Doutor em Educação pela Universidade de São Paulo (USP). Professor Associado do Instituto de Biologia da Universidade Federal da Bahia (UFBA). Coordenador do Laboratório de Ensino, Filosofia e História da Biologia (LEHFBio). E-mail: charbel.elhani@gmail.com
} 


\section{ARGUMENTATION ABOUT SOCIO-ENVIRONMENTAL PROBLEMS IN BIOLOGY TEACHING}

ABSTRACT: Teaching argumentation in scientific education at all levels can facilitate the science learning process and contribute to develop critical thinking and improve people's decision making, among other benefits. Working on the assumption that the knowledge in argumentation is crucial for professional activities, we discuss the use of socio-scientific issues (SSI) in order to promote argumentative skills in an extension course for undergraduate Biological Sciences students. Through models of argumentation analysis, we have assessed the content and structure of the arguments developed by the students. The results have indicated that the socio-scientific issues used have supported the learning and practice of the bases of argumentation. However, there was some limitation as to the quality of the arguments. This indicates the need of further investment in teaching strategies which would apply scientific knowledge to social problems, as well as the valorization of the explicit instruction based on ethical and political argumentation in the Biology curriculum.

Keywords: Socio-Scientific Issues. Argumentation. Toulmin's Argument Model. Farming and livestock.

\section{INTRODUCุ̃̃O}

Em geral, o ato de argumentar representa um modo de pensar e de se expressar retórica ou logicamente ${ }^{1}$, de forma a defender e negociar ideias, ou mesmo fundamentar uma opinião com razões. A capacidade de argumentação de uma pessoa está vinculada à sua compreensão de como apresentar as premissas de modo claro e organizar os elementos do discurso argumentativo de modo integrado, visando ao convencimento do seu interlocutor acerca da conclusão (DRIVER; NEWTON; OSBORNE, 2000; WESTON, 2009). Devido ao seu uso na comunicação científica, a argumentação é importante para a prática da ciência e a construção e a compreensão de seus produtos, por exemplo, teorias e modelos, assim como de seus métodos (OSBORNE, 2005; SASSERON; CARVALHO, 2011). Além disso, ela é considerada uma atividade essencial em processos sociais relacionados à comunicação e à aprendizagem das ciências (SÁ; QUEIROZ, 2007; NASCIMENTO; VIEIRA, 2008; LIMATAVARES; MORTIMER; EL-HANI, 2009).

$\mathrm{Na}$ literatura sobre o assunto, são apontadas muitas vantagens do uso da argumentação na educação científica. Aqui, abordaremos duas que nos parecem mais relevantes. Primeiramente, na formação do estudante como cidadão, a aprendizagem da argumentação 
pode auxiliá-lo a interagir e aperfeiçoar sua prática participativa na sociedade. Isso porque, no processo argumentativo, o estudante aprende a construir, justificar e avaliar as evidências, alternativas e validade das afirmações e a estabelecer contra-argumentos para uma dada proposição (SARDÀ-JORGE; SANMARTÍ-PUIG, 2000; SADLER; DONNELLY, 2006; HENAO; STIPCICH, 2008; WESTON, 2009). Essa aprendizagem, por sua vez, constitui uma condição para o diálogo e a participação democrática de forma esclarecida e consciente (NASCIMENTO; VIEIRA, 2008). Nesse sentido, Costa (2008, p. 6) afirma que:

\footnotetext{
Em síntese, consideramos que o objectivo fundamental do ensino da argumentação é que os estudantes adquiram competências para defender e justificar as suas ideias e opiniões, e que se tornem capazes de compreender, diferenciar e confrontar as ideias e opiniões próprias com as dos outros. (...) Esta aprendizagem implica aprenderem a utilizar determinadas capacidades cognitivas linguísticas como descrever, definir, explicar, justificar, argumentar e demonstrar; ao mesmo tempo que necessitam de saber utilizar capacidades cognitivas básicas da aprendizagem como analisar, comparar, deduzir, inferir e valorar.
}

Aqui percebemos que a aprendizagem da argumentação pode auxiliar no desenvolvimento da capacidade de tomada de decisão (DRIVER; NEWTON; OSBORNE, 2000), uma vez que o estudante com tal preparo é capaz de visualizar a complexidade e a multiplicidade dos diferentes pontos de vista sobre um assunto e avaliar criticamente a informação recebida (SANTOS; MORTIMER; SCOTT, 2001; COSTA, 2008). Nesse sentido, os próprios educadores têm reconhecido que ensinar argumentação é criar condições para a aprendizagem de uma ferramenta útil para o estudante em diferentes contextos de sua vida (SADLER; DONNELLY, 2006).

Em segundo lugar, a argumentação facilita a aprendizagem de conteúdos científicos, por um lado, e da natureza da ciência, por outro. Isso porque o processo argumentativo auxilia o estudante a questionar criticamente afirmações científicas e a compreender as controvérsias, o caráter conjectural, a natureza e o tom dos debates que ocorrem nas comunidades científicas (DRIVER; NEWTON; OSBORNE, 2000; HENAO; STIPCICH, 2008; COSTA 2008). Essa atividade de analisar diferentes situações e dados apresentados, além de aperfeiçoar conhecimentos prévios do estudante (OSBORNE, 2005), contribui para desenvolver o pensamento crítico.

Para completar, um dos objetivos da educação científica é mobilizar conhecimentos científicos de modo a estimular o interesse a seu respeito e propiciar o desenvolvimento da capacidade argumentativa 
do estudante, para que ele possa fazer uso, de forma crítica e organizada, de tais conhecimentos para lidar com a complexidade dos problemas sociais (SIMONNEAUX, 2007; WESTON, 2009). Como apontam Jiménez-Aleixandre e Frederico-Agraso (2006, p.17):

O raciocínio argumentativo é relevante para o ensino das ciências, pois, para construir modelos, explicações do mundo físico e natural e operar com eles, os estudantes precisam, além de aprender significativamente os conceitos implicados, desenvolver a capacidade de escolher entre distintas opções ou explicações e pensar os critérios que permitem avaliá-las. Esse é, portanto, um dos objetivos do ensino das ciências [...].

Uma estratégia que integra pedagogicamente as duas razões supracitadas é o uso de questões sociocientíficas (QSCs)². Tal estratégia permite considerar a aprendizagem integrada de conteúdos científicos, porque as QSCs estão relacionadas a controvérsias e pontos de vista científicos diferentes e interdisciplinares, o que requer mobilização de conhecimentos de diferentes domínios para elaborar argumentos de qualidade (SADLER, 2004; SIMONNEAUX, 2007). Além disso, atividades de raciocínio sobre questões como as QSCs, que em geral são polêmicas e pouco estruturadas (ou seja, abertas; em inglês, open-ended), envolvem, na tomada de decisão, além de conhecimentos relacionados a várias disciplinas, valores, ideologias, aplicação de conteúdos e alguma reflexão moral sobre os problemas sociais associados (JIMÉNEZ-ALEIXANDRE; FREDERICOAGRASO, 2006; SADLER; DONNELLY, 2006; HENAO; STIPCICH, 2008; QUEIROZ; SÁ, 2009).

Contudo, apesar de sua potencial importância no ensino de Ciências (bem como de outras disciplinas escolares), há dificuldades no uso de QSCs em sala de aula, relacionadas, por exemplo, à preocupação de alguns professores mais com a transmissão de conteúdos científicos do que com o oferecimento de atividades que favoreçam a aprendizagem de argumentação (QUEIROZ; SÁ 2009); ou à dificuldade de adoção de atividades que envolvam QSCs em razão de os professores se sentirem pouco preparados para lidar com a interdisciplinaridade requerida para tratar dessas questões (SIMONNEAUX, 2007).

Nesse sentido, Queiroz; Sá (2009); Velloso et al. (2009) e Brito; Sá (2010) sugerem mais esforços na disponibilização de espaços e ações para a promoção de habilidades argumentativas em ambientes de ensino e aprendizagem em nível superior, utilizando QSCs. Assumindo a importância no ensino superior da promoção da argumentação no contexto de QSCs, apresentamos e analisamos neste artigo o uso de uma QSC como meio de favorecer o ensino e a aprendizagem de argumentação e estimular sua prática no ensino superior de Biologia. 


\section{MÉTODO}

A pesquisa foi conduzida como um estudo qualitativo realizado no contexto do Ensino Superior de Biologia, mais especificamente, analisando-se a prática argumentativa no âmbito de um Curso de Extensão incluído num evento do Programa de Pós-Graduação em Ecologia e Biomonitoramento da Universidade Federal da Bahia, voltado para estudantes da graduação e da pós-graduação. O curso, intitulado "Ética e evolução: análise do uso de animais em atividades humanas", ocorreu entre outubro e novembro de 2011.

O curso, com carga horária de $40 \mathrm{~h}$, foi ministrado por dois doutorandos em Ecologia e acompanhado por cinco tutores. As primeiras quatro aulas foram subdivididas em aproximadamente três horas destinadas às aulas expositivas dialogadas e duas horas para as sessões tutoriais. Além disso, foram disponibilizadas três horas e meia (semanais) para reuniões dos estudantes com os tutores, em atividades extraclasses. Na última aula, com duração de seis horas, o período foi dividido entre a síntese das aulas anteriores e a apresentação oral das equipes de estudantes, com discussão dos resultados das análises do caso proposto para estudo (ver abaixo).

Os temas abordados nas aulas foram: história e filosofia do pensamento evolutivo, fundamentos do conhecimento evolutivo e sua aplicação no cotidiano, filogenia da dor e fisiologia animal comparada, fundamentos de ética aplicada, com ênfase em éticas ambiental e animal.

A QSC utilizada foi desenhada na forma de um caso, com base em critérios propostos por Lima e Linhares (2008) e Velloso et al. (2009), incluindo: apresentação de um problema aberto (pouco estruturado), em forma de narrativa; que contemple uma questão de conflito, atual, relevante no contexto brasileiro; que desperte o interesse dos estudantes; que leve a uma tomada de decisão possível para os estudantes; que considere conhecimentos prévios e nível cognitivo dos estudantes; e que tenha utilidade pedagógica no método de ensino empregado.

O caso apresentado aos estudantes do curso abordou a atividade agropecuária de corte em grande escala e os impactos ambientais a ela associados. O Quadro 1 apresenta o caso elaborado para a atividade de argumentação. Esse caso foi apresentado no primeiro dia do curso, e as equipes buscaram resolvê-lo, ao longo do mesmo, escolhendo uma das opções existentes. Após o fim do 
terceiro dia de aula expositiva, foi entregue um complemento do caso, para que as equipes refletissem sobre os aspectos éticos do mesmo, enquanto elaboravam uma solução.

QUADRO 1: Caso apresentado para as equipes no curso de extensão.

\section{Atividade pecuária e problemas ambientais}

Considerando os principais impactos ambientais da atividade agropecuária de corte, como assoreamento de rios, perda de hábitats, redução de atividade microbiológica do solo, redução de áreas de abrigo e nidificação de animais, desmatamento e perda de biodiversidade, desestruturação física do solo, concentração de gases e de sólidos em suspensão, formação de voçorocas e outros tipos de erosão, aumento de gases de efeito estufa, contaminação de solo e água etc., e o agravamento da degradação ambiental decorrente da atividade de pecuária bovina, suína, ovina e caprina em larga escala, o Governo Federal discute a elaboração de uma Lei que aumenta o recolhimento de taxas e impostos da atividade de pecuarista tradicional de corte em grandes escalas. O recurso obtido deverá ser exclusivamente destinado à recuperação de áreas degradadas pela atividade pecuarista, como incentivo àqueles que desejam mudar de atividade. Além disso, estará incluída nessa Lei uma Política de Pagamento por Serviços Ambientais, como forma de valorizar projetos de conservação de recursos ambientais e garantir a rentabilidade da terra. Alguns países, como Índia e Costa Rica, também discutem a implementação de Lei semelhante, como forma de reduzir a quantidade do consumo de carne "vermelha" nesses países (e as consequências ambientais negativas). A equipe de biólogos ${ }^{3}$ é convidada a participar da discussão e defender, a partir de critérios e resultados de suas pesquisas, seu ponto de vista.

Qual a importância desses impactos na qualidade ambiental? Como esses problemas ambientais afetam a qualidade de vida da sociedade humana? Quais as vantagens e desvantagens da implementação de uma Lei como esta para o Brasil? Considere a recepção dessa proposta pelo público, discutindo, em relação à situação da maioria da população brasileira, aspectos culturais, econômicos, políticos, sociais, ambientais, nutricionais, entre outros.

Lembre-se de que a contribuição da equipe de biólogos deve enfatizar conhecimentos da área de biologia, porque, em uma discussão como essa, há outros especialistas contribuindo com suas áreas.

Quais os benefícios e prejuízos de uma Lei com esses propósitos para pecuaristas e populações de regiões como Pantanal e Amazônia (onde ocorre grande parte dos problemas ambientais citados) e quais as consequências para a melhoria das condições ambientais? 
A decisão que a equipe deverá tomar deverá ser justificada com base em um argumento central, elaborado com conhecimentos e materiais necessários e relevantes para a discussão. Organize a partir do modelo de Toulmin. As opções de decisão são:

a) Sugerir a redução da atividade agropecuária descrita, de acordo com a proposta apresentada. Nessa opção, a equipe concorda com a implementação de uma Lei, a favor de aumento de impostos sobre a atividade pecuarista em larga escala, e com o incentivo a atividades de conservação ambiental. Aceita proposta da forma como é apresentada.

b) Sugerir a substituição da atividade agropecuária descrita por outra que cumpra parte do objetivo de reduzir impactos ambientais. Nessa opção, a equipe concorda com a implementação de uma Lei com propósitos semelhantes ao exposto, mas com algumas alterações, recomendadas pela equipe. Aceita uma Lei que objetiva reduzir impactos ambientais, mas não da forma como é apresentada.

c) Sugerir a alteração da atividade agropecuária descrita, a partir de outro dispositivo. Nessa opção, a equipe não concorda com a implementação de uma Lei com esses propósitos, mas recomenda outra mudança dessa atividade pecuária na forma atualmente apresentada. Não aceita a Lei, mas sugere outro dispositivo para reduzir impactos ambientais.

d) Sugerir a manutenção da atividade agropecuária descrita, da forma atualmente apresentada. Nessa opção, a equipe não concorda com a implementação de uma Lei com esses propósitos e concorda com a situação atual dessa atividade pecuária no Brasil. Não aceita a Lei nem qualquer outra proposta para alteração da atividade.

\section{Complemento do caso, após a terceira aula:}

Agora, a equipe deve ponderar, em sua discussão sobre o caso apresentado, aspectos referentes à consideração humana sobre os outros animais que também são capazes de sentir dor e sofrer. Refletir: Qual a necessidade de existirem animais para fins humanos? Se humanos e outros animais são seres sencientes, há ações humanas que devem considerar animais não humanos junto aos humanos? Quais? Como a sociedade considera os animais não humanos sencientes destinados à atividade agropecuarista em larga escala? Como ocorrem a consideração e o tratamento de animais da pecuária de corte em larga escala? Os animais não humanos que sentem dor devem sofrer para satisfazer que necessidades humanas? ${ }^{4}$ 
Reunidos em equipe, os estudantes deveriam optar por uma entre quatro opções de tomada de decisão propostas na descrição do caso e justificar sua decisão, utilizando o modelo de argumento de Toulmin (TOULMIN, 2006; daqui em diante, MAT) como base para a estruturação dos argumentos de cada equipe. A Figura 1 apresenta o MAT.

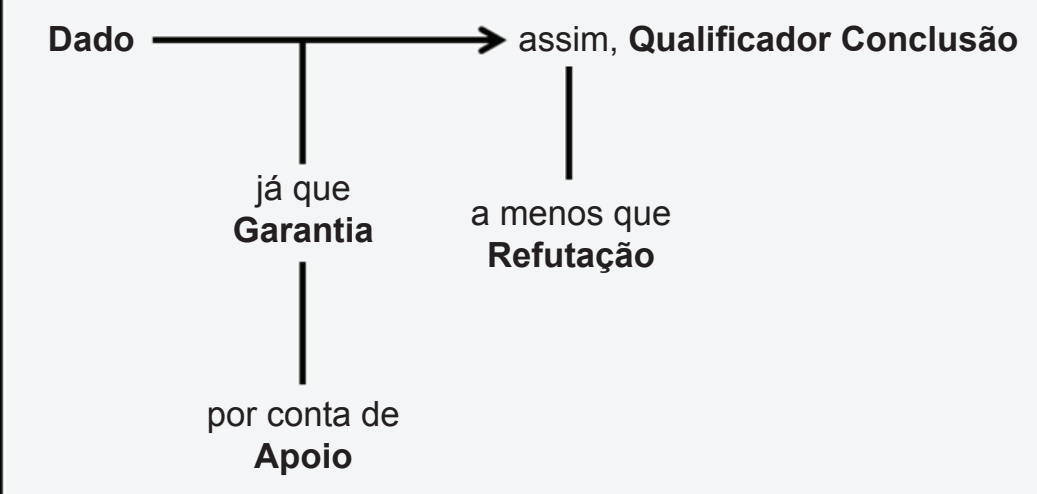

FIGURA 1: Modelo de argumento de Toulmin (modificado de SÁ; QUEIROZ, 2007).

De acordo com esse modelo, os elementos do argumento são: dado (D), garantia $(\mathrm{G})$, apoio $(\mathrm{A})$, qualificador $(\mathrm{Q})$, refutação (R), conclusão (C). Os dados (D), também denominados alegações ou fatos, são afirmações (informações factuais) que fundamentam uma conclusão. As garantias $(G)$ são afirmações que fornecem informações complementares ou que ilustram os dados, e funcionam como garantia que conecta os dados apresentados à conclusão. Os apoios (A) são bases teóricas para as garantias que justificam ou exemplificam um dado. As refutações (R) são afirmações que se opõem aos dados ou às garantias, indicando circunstâncias em que as garantias não se aplicam ou condições de exceção. Os qualificadores (Q) são elementos que modulam o dado, indicando circunstâncias específicas em que o argumento é válido e, logo, os limites de sua validade. A conclusão (C) é aquilo que se procura estabelecer com a argumentação (Para mais detalhes, ver Toulmin, 2006; Driver; Newton; Osborne, 2000).

Participaram dessa atividade, inicialmente, 18 e, ao final, 12 estudantes, incluindo uma bióloga que era também mestre em Ecologia; três biólogas que faziam mestrado na área de biodiversidade (Ecologia e Zoologia); duas biólogas recém-graduadas; cinco 
estudantes dos últimos semestres de um curso de graduação em Biologia; e uma estudante de Veterinária. Essas estudantes se organizaram em cinco equipes. Consideramos como requisito necessário para a inscrição no curso conhecimentos prévios sobre biologia geral e história e epistemologia da biologia, visando facilitar o desenvolvimento das habilidades argumentativas. Para isso, foram selecionados apenas estudantes que haviam cursado duas disciplinas ("Biologia geral" e "Evolução do pensamento científico") que contemplam esses conteúdos no currículo de Biologia da universidade em que foi conduzido o estudo. Inicialmente, foram formados grupos de três a seis estudantes, para possibilitar discussões em que todos pudessem colaborar na construção do argumento (COSTA, 2008).

$\mathrm{O}$ caso foi distribuído entre as equipes, juntamente com materiais (artigos acadêmicos e capítulos de livros sobre a atividade agropecuária no Brasil), para maior familiarização com o principal tema envolvido (agropecuária). Além disso, foi entregue, para cada equipe, um CD contendo materiais acadêmicos sobre ética ambiental, ética animal, biologia evolutiva e argumentação. No primeiro dia, foi ministrada uma aula sobre fundamentos da argumentação na comunicação científica e elementos do argumento com base no MAT. Em todos os dias, houve momentos de reuniões das equipes, com acompanhamento de tutores para discussão sobre a solução do caso. Além disso, foram feitas sugestões para o planejamento de reuniões semanais extraclasse das equipes, bem como para a condução de estudos individuais para a solução do caso. A decisão final sobre essas últimas reuniões e os estudos individuais coube aos alunos. Ao fim do curso, cada equipe fez uma apresentação oral e um texto escrito referentes à resolução do caso, com posterior debate sobre seus posicionamentos. Solicitamos que as equipes organizassem, na medida do possível, seus argumentos escritos com base no MAT.

Para a coleta de dados, utilizamos os argumentos escritos das equipes, contendo a solução do caso. Além disso, a apresentação oral e a discussão foram filmadas. Os estudantes também avaliaram sua aprendizagem e o curso, respondendo a um questionário ${ }^{5}$ ao fim do mesmo.

$\mathrm{Na}$ análise do argumento, partimos do MAT para a realização de uma análise estrutural dos argumentos (ver ERDURAN; SIMON; OSBORNE, 2004) e, assim, para uma avaliação com especial atenção ao nível de complexidade do argumento, conforme Erduran, Simon e Osborne (2004), e à quantidade de justificativas, conforme Jiménez-Aleixandre (2005). 
Após identificar os elementos dos argumentos, organizamos e contabilizamos tipos e frequências de combinações entre eles na apresentação escrita de cada equipe. Argumentos que possuíam menor número de combinações ou ausência de combinações com refutações e qualificadores foram considerados de baixa complexidade. Por sua vez, argumentos que possuíam maior número de combinações entre elementos ou presença de refutações e qualificadores foram considerados de maior complexidade, assumindo-se que isso refletia maior domínio das habilidades argumentativas. Com relação a esse último ponto, cabe notar que a capacidade de elaborar refutações é considerada um dos principais critérios de avaliação da qualidade da argumentação (SADLER; DONNELLY, 2006; SIMONNEAUX, 2007).

As justificativas são compostas pelos elementos garantia e apoio. O termo "justificativa” é usado quando o argumento possui uma estrutura em que esses dois elementos ( $\mathrm{G}$ e A) se apresentam indiferenciados (JIMÉNEZ-ALEIXANDRE; PEREIRO-MUÑOZ, 2002). Isso geralmente ocorre em QSCs ou em outras situações discursivas em que há dificuldade de distinguir entre justificativas referentes a informações complementares que conectam dados a uma conclusão (garantias) e a dados que indicam uma base teórica para fornecer suporte a uma garantia (apoios) (ERDURAN; SIMON; OSBORNE, 2004; SASSERON; CARVALHO, 2011). É importante destacar que justificativas são essenciais para a sofisticação e a robustez de um argumento, porque a presença delas constitui um dos meios que possibilitam a aceitação de uma tese (JIMÉNEZALEIXANDRE, 2005). Assim, analisamos a extensão em que os estudantes fundamentavam seus posicionamentos com base em dados, garantias e apoios e, por conseguinte, suas capacidades de organizar ideias em argumentos coerentes e logicamente consistentes (SADLER; DONNELLY, 2006).

O MAT permite uma análise da estrutura de um argumento, mas não do contexto, da coerência e da retórica dos argumentos. Por essa razão, realizamos uma análise complementar, utilizando o "Modelo de Análise de Argumentação Aplicável a Processos de Resolução de Questões Sócio-científicas", proposto por Sá $(2010)^{6}$. Esse modelo nos permitiu avaliar o conteúdo e a qualidade do argumento, considerando a distinção de aspectos envolvidos no argumento e fontes de evidência adotadas, conforme Brito; Sá (2010) e Sá; Queiroz (2011). 
A partir desse modelo, fizemos a avaliação da natureza predominante do argumento, classificando-os em seis categorias: ambiental (relacionada com problemas ambientais); econômica (relacionada a vantagens e desvantagens econômicas); ética animal (relacionada com o sofrimento de animais); política (relacionada a legislações ou ações governamentais); social (relacionada à qualidade da vida humana); outras (quando não foi possível definir a natureza ou quando não havia correspondência com nenhuma das categorias anteriores, mas a frequência de ocorrência no estudo era baixa). Em relação à origem das informações, organizamos categorias de acordo com as fontes de evidências citadas pelos grupos (SÁ, 2010), como veremos nos resultados.

No questionário de avaliação da aprendizagem e do curso, consideramos no presente estudo somente a seguinte questão fechada respondida pelos estudantes: "Qual sua opinião sobre o uso da argumentação para organizar e defender ideias?”. Para responder à questão, os estudantes podiam assinalar uma ou mais das seguintes opções: interessante; importante; útil; simples; irrelevante; desnecessário; complicado; inútil; outros. Além disso, eles dispunham de um espaço de cinco linhas para fazer comentários. Após a apresentação oral e discussão das equipes, os participantes expuseram suas impressões sobre o uso do MAT para a organização das informações referentes ao caso e à estruturação do argumento.

O texto elaborado por cada equipe foi utilizado como base para a organização dos dados em tabelas. As apresentações orais e discussões, assim como as respostas ao questionário, foram utilizadas como fontes de informações complementares para as análises dos resultados obtidos.

\section{RESULTADOS E DISCUSSÃO}

As cinco equipes apresentaram seus respectivos argumentos como possíveis soluções para o caso. Como pode ser visto na Tabela 1, a equipe $A$ apresentou apenas dois argumentos, sendo um de média e outro de alta complexidade. A equipe $\mathrm{B}$ apresentou três argumentos, um de baixa, um de média e um de alta complexidade. A equipe $C$ apresentou um argumento de baixa e três de alta complexidade. $\mathrm{A}$ equipe $\mathrm{D}$ foi a que apresentou mais argumentos (oito), sendo cinco de baixa e três de média complexidade. E, por fim, a equipe $\mathrm{E}$ apresentou dois argumentos de baixa e quatro de alta complexidade. 
TABELA 1: Frequência de combinações de elementos identificadas nos argumentos apresentados por cada equipe, em ordem de complexidade.

\begin{tabular}{|c|c|c|c|c|c|c|c|c|}
\hline & \multicolumn{2}{|c|}{ Complexidade / Equipe } & \multirow{2}{*}{$\begin{array}{l}\text { A } \\
0\end{array}$} & \multirow[t]{2}{*}{ B } & \multirow[t]{2}{*}{ C } & \multirow{2}{*}{$\begin{array}{l}\text { D } \\
0\end{array}$} & \multirow[t]{2}{*}{$\mathbf{E}$} & \multirow{2}{*}{$\begin{array}{c}\text { Total } \\
1\end{array}$} \\
\hline & \multirow{3}{*}{ Baixa } & DC & & & & & & \\
\hline & & DGC & 0 & 1 & 1 & 5 & 0 & 7 \\
\hline & & DCR & 0 & 0 & 0 & 0 & 1 & 1 \\
\hline & \multirow{2}{*}{ Média } & DGAC & 0 & 0 & 0 & 2 & 0 & 2 \\
\hline & & DGRC & 1 & 1 & 0 & 1 & 0 & 3 \\
\hline & \multirow{2}{*}{ Alta } & DGROC & 0 & 1 & 0 & 0 & 0 & 1 \\
\hline$\downarrow$ & & DGAROC & 1 & 0 & 3 & 0 & 4 & 8 \\
\hline & \multicolumn{2}{|c|}{ Total de argumentos } & 2 & 3 & 4 & 8 & 6 & 23 \\
\hline
\end{tabular}

Legenda: D: dado; G: garantia; A: apoio; R: refutação; Q: qualificador; C: conclusão.

A partir desses dados, podemos ressaltar alguns pontos que nos parecem centrais: apenas o número de argumentos não foi capaz de indicar a qualidade da argumentação, uma vez que a equipe $\mathrm{D}$, que mais apresentou argumentos, não construiu qualquer argumento com combinações complexas de seus elementos, como também foi observado nos estudos de Velloso; Sá; Queiroz (2007) e Nascimento; Vieira (2008). As combinações DGRC e DGC apareceram em um maior número de equipes e, de fato, elas são estruturas muito comuns nos argumentos, porque, de forma geral, um argumento mínimo se organiza com duas premissas e uma conclusão (trata-se, nesse caso, do silogismo categórico, SALMON, 2010). As combinações DC e DCR (encontradas na solução proposta pela equipe E) não exibem justificativas para dados informados, o que pode indicar uso de argumento de autoridade, na medida em que isso pode resultar de as estudantes presumirem que o dado, por si só, é suficiente para extrairse ou inferir-se uma conclusão.

Quanto à quantidade de justificativas para cada argumento, destacamos, na Tabela 2, que todas as equipes apresentaram pelo menos um argumento contendo apenas dados, sem justificativas para suas conclusões, o que pode indicar, como mencionado acima, o uso de argumentos de autoridade.

Para Osborne (2005), a presença de argumentos sem justificativas pode ser vista como um primeiro estágio de sua organização. A apresentação de dados acompanhados, ao menos, por garantias reconhece as evidências da ideia principal, o que 
geralmente indica maior qualidade do argumento (OSBORNE, 2005). Nesse caso, o argumento poderia ser de melhor qualidade se os conhecimentos básicos sobre o assunto fossem mobilizados para justificar e fundamentar os dados evidenciados.

No entanto, as equipes também elaboraram argumentos contendo a combinação de dado(s) e garantia(s). O uso de apoios como justificativa ocorreu nas equipes $\mathrm{A}, \mathrm{E}, \mathrm{C}$ e, em menor número, em $\mathrm{D}$, sendo que a equipe $\mathrm{C}$ apresentou três argumentos (de um total de quatro) compostos por DGA. A equipe B não apresentou qualquer argumento contendo apoios em suas justificativas. Isso enfraqueceu seus argumentos, exatamente por não haver entre eles qualquer argumento com a combinação de dado(s) com garantia(s) e apoio(s), o que geralmente indica maior sofisticação e qualidade argumentativa.

TABELA 2: Justificativas identificadas nos argumentos apresentados por cada equipe.

\begin{tabular}{ccccc}
\hline Equipe & Argumento & $\begin{array}{c}\text { D: somente } \\
\text { dado(s) }\end{array}$ & $\begin{array}{c}\text { DG: dado(s) } \\
\text { com } \\
\text { garantia(s) }\end{array}$ & $\begin{array}{c}\text { DGA: } \\
\text { dado(s) com } \\
\text { garantia(s) }\end{array}$ \\
apoio(s)
\end{tabular}


Como também podemos notar, todas as equipes apresentaram justificativas para suas proposições. Particularmente para aquelas equipes que apresentaram a combinação DGA, podemos dizer que o processo argumentativo contribuiu para organizar e aprofundar os conhecimentos envolvidos nesses argumentos.

Apesar da presença de argumentos sofisticados em termos estruturais, o contexto de apresentação do caso, num curso de 40 horas, pode ter dificultado o desenvolvimento de combinações mais complexas, como DGAQRC, ou com maior número de justificativas. Nesse sentido, para a melhoria da qualidade dos argumentos elaborados pelos estudantes, será importante, em versões futuras do curso, disponibilizar, no planejamento didático, mais tempo para a discussão e o acompanhamento do desenvolvimento da argumentação por cada equipe.

Em geral, com relação aos aspectos mobilizados, podemos notar, na Tabela 3, que todas as equipes enfocaram, em seus argumentos, grande número de aspectos ambientais (como poluição, conservação, interações ecológicas, etc.) do caso. Isso era esperado, já que a maioria das estudantes é da área de Ciências Biológicas. Além disso, foi solicitado que cada equipe elaborasse argumentos como se estivessem a exercer seus papéis profissionais como biólogos. Isso favoreceu a maior presença de aspectos ambientais e, em particular, de conhecimentos de Ecologia.

Aspectos sociais (relacionados à qualidade de vida humana) foram abordados também em grande número, quando os grupos discutiam questões nutricionais e de saúde relacionadas ao consumo ou não de carne por seres humanos, ou às condições inadequadas e insalubres a que trabalhadores da atividade agropecuária estão expostos cotidianamente. Aspectos econômicos, relacionados à produção e ao mercado da agropecuária, também foram destacados por todas as equipes. As equipes A, C, D e, em menor medida, E também mobilizaram preocupações referentes à ética animal, principalmente relacionadas com os maus-tratos dos animais e com a capacidade destes de sentir dor e sofrer, porém sempre de uma perspectiva bem-estarista ${ }^{7}$. Esse aspecto foi consonante com um dos objetivos da resolução do caso, uma vez que, a partir do complemento do caso, após aula introdutória sobre ética animal (terceira aula), esperávamos que houvesse alguma mobilização dessas preocupações para a resolução do caso.

Por fim, aspectos políticos (relacionados a legislações ou ações governamentais) foram os que menos ocorreram nos argumentos, 
com exceção da equipe E, que expôs suas conclusões, suas refutações e seus qualificadores quase que completamente no âmbito das mudanças políticas para melhor efetividade das soluções propostas pela equipe. Isso ocorreu porque, nessa equipe, havia uma estudante com experiência de trabalho em órgão ambiental público. No entanto, aspectos políticos foram discutidos por todos (juntamente com aspectos éticos, ambientais e sociais), após a apresentação de cada equipe. Na categoria “Outro", inserimos os elementos do argumento em que não foi possível definir um aspecto principal ou quando este não correspondeu a nenhuma das categorias anteriores.

TABELA 3: Principal aspecto identificado nos elementos do argumento ${ }^{8}$.

\begin{tabular}{|c|c|c|c|c|c|}
\hline $\begin{array}{l}\text { Aspecto I } \\
\text { Equipe }\end{array}$ & A & B & C & D & E \\
\hline Ambiental & $\begin{array}{c}8 \\
(3 \mathrm{D}, 2 \mathrm{G}, 1 \mathrm{~A}, \\
1 \mathrm{R}, 1 \mathrm{C})\end{array}$ & $\begin{array}{c}2 \\
(1 D, 1 G)\end{array}$ & $\begin{array}{c}10 \\
(3 \mathrm{D}, 2 \mathrm{G}, 1 \mathrm{~A}, \\
2 \mathrm{R}, 2 \mathrm{Q})\end{array}$ & $\begin{array}{c}20 \\
(7 D, 8 G, 3 A \text {, } \\
2 C)\end{array}$ & $\begin{array}{c}18 \\
(7 D, 6 G, 4 A \text {, } \\
1 C)\end{array}$ \\
\hline Econômica & $\begin{array}{c}1 \\
(1 \mathrm{R})\end{array}$ & $\begin{array}{c}8 \\
(2 D, 1 G, 5 R)\end{array}$ & $\begin{array}{c}\mathbf{5} \\
(1 \mathrm{D}, 3 \mathrm{G}, 1 \mathrm{R})\end{array}$ & $\begin{array}{c}9 \\
(4 D, 3 G, 2 C)\end{array}$ & $\begin{array}{c}\mathbf{6} \\
(2 \mathrm{D}, 1 \mathrm{~A}, 1 \mathrm{R}, \\
2 \mathrm{C})\end{array}$ \\
\hline $\begin{array}{c}\text { Ética } \\
\text { animal }\end{array}$ & $\begin{array}{c}5 \\
(2 \mathrm{D}, 1 \mathrm{G}, 1 \mathrm{R} \text {, } \\
1 \mathrm{C})\end{array}$ & 0 & $\begin{array}{c}1 \\
\text { (1D) }\end{array}$ & $\begin{array}{c}\mathbf{5} \\
(2 \mathrm{D}, 2 \mathrm{G}, 1 \mathrm{C})\end{array}$ & $\begin{array}{c}1 \\
(1 \mathrm{C})\end{array}$ \\
\hline Política & $\begin{array}{c}2 \\
(2 C)\end{array}$ & $\begin{array}{c}1 \\
(1 C)\end{array}$ & ${ }^{2}(10,1 C)$ & $\begin{array}{c}1 \\
\text { (1C) }\end{array}$ & $\begin{array}{c}27 \\
(1 \mathrm{D}, 1 \mathrm{G} \\
11 \mathrm{R}, 30 \\
11 \mathrm{C})\end{array}$ \\
\hline Social & $\begin{array}{c}1 \\
(1 \mathrm{R})\end{array}$ & $\begin{array}{c}4 \\
(2 \mathrm{D}, 2 \mathrm{G})\end{array}$ & $\begin{array}{c}7 \\
(1 \mathrm{D}, 1 \mathrm{G}, 2 \mathrm{~A}, \\
1 \mathrm{R}, 2 \mathrm{Q})\end{array}$ & $\begin{array}{c}14 \\
(7 \mathrm{D}, 4 \mathrm{G}, 1 \mathrm{R}, \\
2 \mathrm{C})\end{array}$ & $\begin{array}{c}7 \\
(4 \mathrm{D}, 1 \mathrm{R}, 2 \mathrm{C})\end{array}$ \\
\hline Outro & $\begin{array}{c}1 \\
(1 \mathrm{R})\end{array}$ & $\frac{2}{(1 G, 10)}$ & $\frac{2}{(1 G, 1 C)}$ & $\begin{array}{c}7 \\
(2 \mathrm{D}, 2 \mathrm{G}, 3 \mathrm{C})\end{array}$ & $\begin{array}{c}2 \\
(1 D, 10)\end{array}$ \\
\hline Total & 18 & 17 & 27 & 56 & 61 \\
\hline
\end{tabular}

Legenda: D: dado; G: garantia; A: apoio; R: refutação; Q: qualificador; C: conclusão.

Em suma, as equipes mobilizaram conhecimentos relacionados a vários campos, sendo que, na equipe $\mathrm{A}$, predominou o enfoque em ética $\mathrm{e}$ ambiente, na equipe $\mathrm{B}$, enfoque socioeconômico, na equipe $\mathrm{C}$, o enfoque socioambiental, na equipe $\mathrm{D}$, ambiental e socioeconômico, na equipe $\mathrm{E}$, político e ambiental. Com isso, notamos que a resolução desse caso com o emprego da argumentação foi capaz de suscitar nas equipes um esforço de integrar conhecimentos de diversas áreas. Podemos afirmar, pois, que 
a QSC proposta foi capaz de promover uma abordagem interdisciplinar. Além disso, durante as discussões, as estudantes enfatizaram como essas estratégias (uso de argumentação e QSC em sala de aula) contribuíram para uma aprendizagem mais ampla e contextualizada.

Sadler e Donnelly (2006), que avaliaram a argumentação de estudantes de ensino médio sobre QSCs relacionadas a temas de genética, advertiram que a apropriação de um nível básico de conhecimento sobre um tema não é suficiente para que os estudantes venham a considerá-lo nas decisões sobre tais questões. Isso porque, de forma geral, o estudante raramente se encontra preparado para mobilizar esse conhecimento. Conrado et al. (2011), ao avaliarem o uso do conhecimento evolutivo na tomada de decisão sobre QSCs, também perceberam que os conhecimentos relativos a um determinado assunto nem sempre são aplicados quando estes são necessários para uma tomada de decisão. No caso do curso discutido neste artigo, conhecimentos de evolução e de ética ambiental e animal aplicados ao cotidiano, apesar de terem sido trabalhados, estiveram pouco presentes nos argumentos apresentados pelas equipes.

Os conhecimentos de ética e evolução que esperávamos que as estudantes mobilizassem para a solução do caso são aqueles que foram mencionados durante o curso, como valor intrínseco dos seres vivos e do ecossistema; senciência e princípio de igualdade de consideração de animais não humanos no tocante a interesses primários em comum com animais humanos; princípio da não maleficência e da beneficência no tratamento de animais da pecuária; desperdício e contaminação de recursos naturais no crescimento de herbívoros para serem consumidos pelos humanos, que poderiam consumir diretamente o nível trófico inferior; redução de variabilidade genética e aumento de vulnerabilidade devido à monocultura de grãos destinados à agropecuária; aumento da resistência de pragas a pesticidas em cultivos; aumento da resistência bacteriana a antibióticos e risco de contaminação de trabalhadores e consumidores da carne. Apesar de esses assuntos terem sido discutidos durante as aulas, e de os tutores também terem destacado para as equipes os principais temas do curso, de forma geral, elas enfocaram mais os aspectos ambientais e econômicos do caso, provavelmente pela facilidade de encontrar dados e justificativas para argumentos voltados para tais aspectos.

Apesar da baixa mobilização de conhecimentos de evolução e ética ambiental e animal, notamos, como ponto positivo, que muitos outros conhecimentos, de ecologia, economia, política, foram mobilizados. Nesse sentido, o conhecimento sobre o contexto que 
envolve o tema principal abordado no caso, sobretudo aquele de áreas distintas da formação do estudante, auxiliou o desenvolvimento de melhores argumentos pelas estudantes.

Quando examinamos a diversidade de conhecimentos mobilizados, proveniente de várias áreas, para o desenvolvimento dos argumentos pelas equipes, notamos que o uso da QSC no contexto do curso foi eficaz para promover essa interação entre conhecimentos diversos. Isso pode ter se refletido em uma melhor qualidade dos argumentos, considerando um uso variado de perspectivas distintas. Além disso, o domínio do tema, juntamente com a mobilização de conhecimentos básicos sobre o contexto em que a QSC se insere, aumenta a complexidade dos argumentos (SADLER; DONNELLY, 2006).

Com base no exposto acima, nossos resultados sugerem a necessidade de uma maior atenção ao ensino de ética ambiental e animal no currículo dos cursos de Biologia. Por sua vez, sugerimos uma presença mais transversal de evolução nas várias disciplinas dos cursos de Biologia, bem como uma maior ênfase sobre sua aplicação em QSCs.

Em relação às fontes das evidências apresentadas nos dados, nas justificativas e nas refutações, as equipes C e E utilizaram, em geral, publicações acadêmicas e de órgãos/instituições públicos, como a Organização das Nações Unidas para a Agricultura e Alimentação (FAO), enquanto as equipes A, B e D fizeram uso de sites não acadêmicos ou jornais de publicidade (Tabela 4). Uma maior diversidade de fontes diferentes esteve associada com os argumentos de maior complexidade, i.e., contendo maior combinação dos elementos do argumento.

TABELA 4: Origem das informações usadas nos argumentos das equipes.

\begin{tabular}{lccccc}
\hline \multicolumn{1}{c}{ Evidência / Equipe } & A & B & C & D & E \\
\hline Artigo completo/ Livro/ Tese (acadêmico) & 0 & 0 & 4 & 1 & 3 \\
\hline Órgão/ Instituição Públicos & 0 & 0 & 1 & 2 & 1 \\
\hline Sites não acadêmicos/ Jornal on-line & 1 & 3 & 0 & 5 & 1 \\
\hline Anais de Congresso/ Encontro (acadêmico) & 0 & 0 & 1 & 0 & 0 \\
\hline $\begin{array}{l}\text { Experiência/ Conhecimento próprio } \\
\text { Outra (não identificada): autores citados e não } \\
\text { referenciados }\end{array}$ & 1 & 0 & 0 & 1 & 1 \\
\hline Total de evidências mencionadas & 1 & 1 & 0 & 11 & 9 \\
\hline
\end{tabular}


No entanto, em contraste com os resultados de JiménezAleixandre; Frederico-Agraso (2006) e Velloso; Sá; Queiroz (2007), as estudantes não questionaram a consistência das informações obtidas, levando em conta as fontes de evidências utilizadas. Nossos resultados estiveram mais de acordo com os de Brito; Sá (2010), que também constataram que os estudantes, apesar de apresentarem fundamentos e justificativas para seus dados, muitas vezes não foram capazes de sustentar satisfatoriamente a confiabilidade das informações obtidas. $\mathrm{Na}$ equipe $\mathrm{B}$, uma fonte de dados (site não acadêmico) foi oriunda de uma instituição privada de produção de grãos destinados à pecuária, $\mathrm{O}$ que poderia levar a um enviesamento ideológico do argumento, dado que a fonte, nesse caso, está comprometida, mesmo que indiretamente, com a própria produção da mercadoria a ser comercializada (carne bovina), assunto principal do caso9. $\mathrm{Na}$ equipe $\mathrm{D}$, uma das fontes utilizadas foi um programa de reportagem da grande mídia, que, além de apresentar informações demasiado simplificadas, também pode trazer excessivo enviesamento. Simonneaux (2007) destaca, como um dos principais desafios da argumentação em QSCs, a influência dos meios de comunicação de massa, como obstáculo para a construção de um discurso autônomo pelo estudante. Isso pode ser combatido com uma formação mais crítica e informada, a partir de fontes confiáveis e maior interesse pela origem das informações obtidas. Essa preocupação não se manifestou, contudo, nas estudantes do curso, o que reforça a necessidade de atentar para uma maior capacitação para a avaliação da confiabilidade das informações e ideias utilizadas, e o desenvolvimento de uma opinião própria e, ao mesmo tempo, bem-fundamentada em fontes confiáveis, adequadamente citadas na construção do argumento (COSTA, 2008).

A respeito da indicação de fontes pessoais para dados apresentados, a aplicação de conhecimentos próprios para fundamentar ideias pode ilustrar a experiência das estudantes com o tema principal do caso. A equipe A, por exemplo, para defender a ideia de que, de fato, ainda ocorrem maus-tratos com animais da agropecuária, usou informações sobre o processo de castração bovina, prática rotineira na produção de gado nacional. A equipe $\mathrm{E}$, por sua vez, criticou a existência de legislações que permitem o desmatamento da Floresta Amazônica para a pecuária, mostrando o forte interesse econômico e enviesamento daqueles que aprovam tais leis, como os parlamentares ligados aos latifundiários (a chamada "bancada ruralista" do Congresso Nacional Brasileiro).

$\mathrm{Na}$ Tabela 5, mostramos alguns exemplos que representam a argumentação dos grupos. Nessa tabela, podemos visualizar 
alguns aspectos da organização dos argumentos pelas equipes. Além disso, identificamos alguns elementos de determinado argumento (dado, garantia etc.) da equipe, bem como o significado conferido em sua análise. Trazemos também um fragmento do texto construído pela equipe, e o principal conteúdo atribuído a ele.

TABELA 5: Fragmentos dos argumentos construídos pelas equipes.

\begin{tabular}{|c|c|c|c|}
\hline Equipe & $\begin{array}{l}\text { Elemento do Argumento e } \\
\text { Mensagem Principal }\end{array}$ & Fragmento do Argumento & Conteúdo \\
\hline A & $\begin{array}{l}\text { Dado: Pecuária intensiva contribui } \\
\text { para } 0 \text { agravamento de problemas } \\
\text { ambientais }\end{array}$ & $\begin{array}{l}\text { "[...] observamos impactos } \\
\text { graves no meio ambiente, como: } \\
\text { assoreamento de rios, perda de } \\
\text { biodiversidade, concentração } \\
\text { de gases do efeito estufa e } \\
\text { contaminação do solo, ar e água." }\end{array}$ & Ambiental \\
\hline A & $\begin{array}{l}\text { Garantia: Bovinocultura intensifica } \\
\text { problemas ambientais, como } \\
\text { contribuições para efeito estufa }\end{array}$ & $\begin{array}{l}\text { "Estudos realizados informam } \\
\text { que principalmente a } \\
\text { bovinocultura está contribuindo } \\
\text { significativamente para a } \\
\text { intensificação do efeito estufa, } \\
\text { mais do que as empresas de } \\
\text { transportes." }\end{array}$ & Ambiental \\
\hline A & $\begin{array}{l}\text { Conclusão: Deve haver uma } \\
\text { lei para aumento de impostos } \\
\text { da pecuária e para incentivar } \\
\text { conservação ambiental e educação } \\
\text { ambiental da comunidade }\end{array}$ & $\begin{array}{l}\text { "[...] necessária a implementação } \\
\text { de uma lei a favor do aumento } \\
\text { de impostos sobre a atividade } \\
\text { e incentivo a atividades de } \\
\text { conservação ambiental" [...]." }\end{array}$ & Política \\
\hline A & $\begin{array}{l}\text { Refutação: Exceto se forem } \\
\text { adotados métodos que causem } \\
\text { menos sofrimento aos animais na } \\
\text { agropecuária }\end{array}$ & $\begin{array}{l}\text { "[...] devendo ser desenvolvidas } \\
\text { formas de manejo desses animais, } \\
\text { evitando ao máximo o seu } \\
\text { sofrimento." }\end{array}$ & $\begin{array}{l}\text { Ética } \\
\text { animal }\end{array}$ \\
\hline B & $\begin{array}{l}\text { Dado: } 0 \text { incentivo para a produção } \\
\text { do gado orgânico aumentou com a } \\
\text { crise da vaca louca }\end{array}$ & $\begin{array}{l}\text { "Na Europa, a crise da vaca louca } \\
\text { fez com que a Alemanha tomasse } \\
\text { decisões e assumisse o gado } \\
\text { orgânico definitivamente." }\end{array}$ & Econômica \\
\hline B & $\begin{array}{l}\text { Garantia: A carne não conterá } \\
\text { resíduos oriundos do estresse a } \\
\text { que os animais da agropecuária } \\
\text { tradicional são submetidos }\end{array}$ & $\begin{array}{l}\text { "[...] a carne estará livre de } \\
\text { animais submetidos a alto teor } \\
\text { de estresse por um tratamento } \\
\text { mecânico." }\end{array}$ & Social \\
\hline
\end{tabular}


TABELA 5: (continuação).

\begin{tabular}{|c|c|c|c|}
\hline Equipe & $\begin{array}{l}\text { Elemento do Argumento e } \\
\text { Mensagem Principal }\end{array}$ & Fragmento do Argumento & Conteúdo \\
\hline B & $\begin{array}{l}\text { Conclusão: A atividade pecuária } \\
\text { orgânica deve substituir a } \\
\text { atividade pecuária intensiva } \\
\text { tradicional com lei para aumento } \\
\text { de imposto para atividade a } \\
\text { tradicional e incentivo à agricultura } \\
\text { orgânica }\end{array}$ & $\begin{array}{l}\text { "[...] lei e taxa, porém que esse } \\
\text { arrecadamento seja investido em } \\
\text { custos referentes à mudança da } \\
\text { atividade pecuária de corte de } \\
\text { larga escala do tradicional para } \\
\text { orgânico [...]." }\end{array}$ & Política \\
\hline B & $\begin{array}{l}\text { Qualificador: Para evitar } \\
\text { uma mudança brusca, inserir } \\
\text { inicialmente o tratamento do } \\
\text { gado existente como boi verde e, } \\
\text { subsequentemente, a adaptação da } \\
\text { atividade para um gado orgânico }\end{array}$ & $\begin{array}{l}\text { "Antes de haver essa mudança } \\
\text { para o boi orgânico, que esses } \\
\text { bois sejam adaptados para um boi } \\
\text { verde, mais solto [...]." }\end{array}$ & Outra \\
\hline C & $\begin{array}{l}\text { Dado: Existe demanda } \\
\text { internacional por combustíveis } \\
\text { alternativos }\end{array}$ & $\begin{array}{l}\text { "[...] aumento na demanda } \\
\text { mundial por combustíveis } \\
\text { alternativos, investimentos } \\
\text { estrangeiros no setor." }\end{array}$ & Econômica \\
\hline C & $\begin{array}{l}\text { Garantia: Em São Paulo, já ocorre } \\
\text { a substituição de atividade } \\
\text { pecuarista por agroindústria de } \\
\text { cana-de-acúcar com resultados } \\
\text { economicamente positivos }\end{array}$ & $\begin{array}{l}\text { “Esse tipo de substituição já } \\
\text { está acontecendo em diversas } \\
\text { regiões do Estado de São Paulo, } \\
\text { especialmente em Araçatuba e } \\
\text { Presidente Prudente, polos da } \\
\text { pecuária nacional.” }\end{array}$ & Econômica \\
\hline C & $\begin{array}{l}\text { Conclusão: A atividade pecuária } \\
\text { intensiva deve ser substituída por } \\
\text { cultivo rotativo de cana-de-açúcar } \\
\text { verde a partir de lei para repasse } \\
\text { de subsídios e assistência técnica } \\
\text { para a mudança de atividade }\end{array}$ & $\begin{array}{l}\text { “Substituição [gradual e parcial] } \\
\text { da atividade pecuária intensiva } \\
\text { por cultivo rotativo de cana-de- } \\
\text { açúcar verde." }\end{array}$ & Política \\
\hline C & $\begin{array}{l}\text { Qualificador: Deve ocorrer o apoio } \\
\text { técnico e incentivo à cultura } \\
\text { rotativa para evitar a monocultura } \\
\text { de cana }\end{array}$ & $\begin{array}{l}\text { "[...] incentivar a prática da } \\
\text { cultura rotativa através de } \\
\text { subsídios, contemplando as } \\
\text { necessidades regionais." }\end{array}$ & Ambiental \\
\hline
\end{tabular}


TABELA 5: (continuação).

\begin{tabular}{|c|c|c|c|}
\hline Equipe & $\begin{array}{l}\text { Elemento do Argumento e } \\
\text { Mensagem Principal }\end{array}$ & Fragmento do Argumento & Conteúdo \\
\hline D & $\begin{array}{l}\text { Dado: São extensas as áreas de } \\
\text { ocupação por rebanhos bovinos no } \\
\text { Brasil }\end{array}$ & $\begin{array}{l}\text { "No Brasil, a terra ocupada } \\
\text { para a pecuária equivale a uma } \\
1 \text { cabeça de gado para mais de } \\
1 \text { hectare." }\end{array}$ & Outra \\
\hline D & $\begin{array}{l}\text { Garantia: Pelo método de Voisin, há } \\
\text { um confinamento adequado em até } 30 \\
\text { cabeças por } 2,5 \text { hectare }\end{array}$ & $\begin{array}{l}\text { “Voisin determinou que, para } \\
\text { vacas que se alimentam de } 40 \\
\mathrm{~kg} \text { a } 60 \mathrm{~kg} \text { de pastagem por } \\
\text { dia em } 8 \mathrm{~h} \text { e produzem até } 10 \\
\mathrm{~kg} \text { de leite diário, necessita de } \\
120 \mathrm{~m}^{2} \text { de pasto bom, ou seja, } \\
\text { podem ser confinadas até } 30 \\
\text { vacas em um espaço de } 2,5 \text { ha } \\
\text { de terra." }\end{array}$ & Econômica \\
\hline D & $\begin{array}{l}\text { Conclusão: Deve-se reduzir } \\
\text { adequadamente a área ocupada pelo } \\
\text { gado }\end{array}$ & $\begin{array}{l}\text { "Assim, a área de terra } \\
\text { ocupada por } 1 \text { cabeça de gado } \\
\text { deve ser diminuída." }\end{array}$ & Outra \\
\hline$D$ & $\begin{array}{l}\text { Conclusão: Animais criados para } 0 \\
\text { abate não devem sofrer }\end{array}$ & $\begin{array}{l}\text { "[...] sofram dor nesse } \\
\text { momento, além de que sejam } \\
\text { criados em boas condições } \\
\text { ambientais (espaço) e de } \\
\text { higiene." }\end{array}$ & $\begin{array}{l}\text { Ética } \\
\text { animal }\end{array}$ \\
\hline $\mathrm{E}$ & $\begin{array}{l}\text { Garantia: Criação de fundos para } \\
\text { empréstimos a produtores pecuaristas } \\
\text { na Amazônia Legal }\end{array}$ & $\begin{array}{l}\text { "Os fundos constitucionais } \\
\text { destinados à Amazônia Legal } \\
\text { emprestam dinheiro a taxas } \\
\text { de juros de } 6 \% \text { a } 10,75 \% \text { ao } \\
\text { ano (bem abaixo da praticada } \\
\text { no mercado, e ainda permitem } \\
\text { descontos de } 15 \% \text { a } 25 \% \text { para } \\
\text { produtores adimplentes)." }\end{array}$ & Política \\
\hline $\mathrm{E}$ & $\begin{array}{l}\text { Apoio: Exemplo de financiamento do } \\
\text { Banco da Amazônia para a pecuária }\end{array}$ & $\begin{array}{l}\text { "Entre } 1989 \text { e 2002, o Banco } \\
\text { da Amazônia emprestou cerca } \\
\text { de U\$ 5,8 bilhões do FNO } \\
\text { (exceto para Mato Grosso e } \\
\text { Maranhão), dos quais pelo } \\
\text { menos US\$ 2,36 bilhões ( } 40 \% \text { ) } \\
\text { foram para a pecuária bovina." }\end{array}$ & Econômica \\
\hline
\end{tabular}


TABELA 5: (continuação).

\begin{tabular}{l|l|l|l}
\hline Equipe & \multicolumn{1}{|c|}{$\begin{array}{c}\text { Elemento do Argumento e } \\
\text { Mensagem Principal }\end{array}$} & Fragmento do Argumento & Conteúdo \\
\hline E & $\begin{array}{l}\text { Conclusão: Implementação de Imposto } \\
\text { de Renda Ecológico }\end{array}$ & $\begin{array}{l}\text { “[..] permitir que pessoas } \\
\text { físicas ou jurídicas que } \\
\text { invistam em projetos } \\
\text { ambientais possam deduzir os } \\
\text { valores investidos do imposto } \\
\text { de renda anual, estimulando } \\
\text { maior aporte de recursos para } \\
\text { a área ambiental." }\end{array}$ & Política \\
\hline E & $\begin{array}{l}\text { Refutação: Resistência política e legal } \\
\text { para a criação do Imposto de Renda } \\
\text { Ecológico }\end{array}$ & $\begin{array}{l}\text { "A proposta de criação do 'IR } \\
\text { Ecológico' encontra resistência } \\
\text { do Ministério da Fazenda, visto } \\
\text { que a gestão ambiental não } \\
\text { é considerada prioridade nos } \\
\text { documentos programáticos } \\
\text { do país, e qualquer proposta } \\
\text { que implique na diminuição de } \\
\text { arrecadação deve se enquadrar } \\
\text { nas diretrizes da LRF (Lei de } \\
\text { Regulaçãa Fiscal).” }\end{array}$ & Política \\
\hline
\end{tabular}

Sobre a questão a respeito do uso da argumentação apresentada no questionário de avaliação do curso, entre as dez estudantes que retornaram o questionário, oito assinalaram as alternativas "importante" e "útil"; sete marcaram também "interessante"; e duas acrescentaram "simples". Algumas comentaram que a abordagem argumentativa contribuiu para seus crescimentos pessoais e profissionais, para ampliar a compreensão sobre diferentes conteúdos e desenvolver argumentos consistentes. Uma delas declarou também: "É umponco complicado se acostumar com esse método, mas quando se compreende, a sua utilidade é incrivel". A partir desses dados, podemos afirmar que a atividade de argumentação com o uso de uma QSC como caso contribuiu para estimular a aprendizagem e o aprofundamento sobre conhecimentos curriculares (como ecologia, fisiologia, evolução) e extracurriculares (como ética, lógica, ciência política), favorecendo o desenvolvimento do pensamento crítico das estudantes. Desse modo, concordamos com Costa (2008, p. 5), quando afirma que: 
Defendemos que a motivação para argumentar corresponda, efectivamente, a uma necessidade sentida pelos alunos. (...) A argumentação na ciência não é oposição e agressividade; é uma forma de discussão colaborativa em que as duas partes estão a trabalhar em conjunto para resolver um problema em que ambos os lados esperam estar de acordo no fim da argumentação.

Em nossa experiência, todos os participantes (estudantes, tutores e professores) afirmaram que o estudo do caso possibilitou a projeção de seus resultados para outros contextos, como também constataram Sasseron; Carvalho (2011) e Simonneaux (2007). Ao fim das discussões, todos concordaram com o fato de que o conhecimento técnico e científico, aprendido pelo biólogo em formação, precisa estar aliado ao conhecimento ético para fundamentar sua ação política como cidadão.

\section{CONSIDERAC̣̃̃ES FINAIS}

Jiménez-Aleixandre; Frederico-Agraso (2006) defendem o ensino explícito sobre como argumentar e analisar um argumento, levando em consideração os valores morais que permeiam sua conclusão, como parte de uma formação crítica que possa esclarecer que nem sempre os conhecimentos científicos são razões suficientes para embasar uma tomada de decisão, mas que, adicionalmente, valores ambientais, econômicos e políticos, por exemplo, se fazem necessários ou estão implícitos na construção de um argumento.

Em particular, na elaboração de argumentos sobre situações reais complexas, tais como as que encontramos nas QSCs, tornamse necessárias a mobilização e a aprendizagem de conhecimentos de diversos campos. No caso da QSC empregada no curso discutido nesse artigo, a atividade de argumentação trouxe à tona tanto conhecimentos vinculados aos currículos dos cursos de Biologia (como ecologia, fisiologia, evolução), quanto conhecimentos raramente presentes em tais currículos (como ética, lógica, ciência política). Apesar de as estudantes não terem recebido capacitação explícita prévia sobre argumentação, por meio dessa atividade, elas conseguiram se colocar no lugar de especialistas para formação de uma opinião sobre o tema e puderam assim perceber as dificuldades e os diferentes aspectos envolvidos na tomada de decisão sobre uma QSC pertinente ao cotidiano de biólogos.

A partir da QSC, também foi possível contribuir para uma formação mais crítica e interdisciplinar das estudantes, bem como o desenvolvimento de diversas habilidades, como: elaboração de 
argumentos para a resolução do caso; integração de diferentes áreas do conhecimento; discussão de valores envolvidos com problemas ambientais; e aprofundamento de diversos tipos de conhecimentos sobre agropecuária.

A resolução da QSC sobre agropecuária propiciou, pois, aprendizagem de argumentação com aplicação de conhecimentos de diversas áreas. Porém, houve ainda dificuldade das estudantes para desenvolver bons argumentos. Por isso, apontamos a importância da capacitação e da criação de espaços e oportunidades para a prática da argumentação. Afinal, o processo argumentativo não é simples: não é suficiente apenas aprender a lógica do processo argumentativo, mas é preciso também praticar a habilidade argumentativa (SARDA-JORGE; SANMARTÍ-PUIG, 2000).

Por fim, as conclusões gerais que alcançamos possibilitam refletir sobre perspectivas futuras, para outros trabalhos sobre argumentação no ensino superior de Biologia. Assim, sugerimos alguns caminhos possíveis a investigar, visando a melhorias no currículo:

1. Maior ênfase sobre o ensino (e a prática) de argumentação e lógica em diferentes momentos do currículo de Biologia, o que é consoante com a nossa visão de que argumentação, diferentemente de um conteúdo qualquer, é um exercício a ser continuamente praticado.

2. Os currículos de Biologia poderiam considerar, de modo mais explícito e claro, as dimensões éticas das ações dos biólogos. Isso significa não apenas inserir discussões éticas em disciplinas como Zoologia, Botânica, Ecologia, Genética etc., mas também a criação de disciplinas relativas à ética animal e ambiental (ver CONRADO; EL-HANI; NUNES-NETO, 2013).

3. Maior ênfase de conteúdos de política ambiental, tanto por meio de disciplinas específicas, como por meio de discussões em disciplinas de Economia Ecológica, Ecologia Geral, Ética etc. Tais conteúdos possibilitam melhor preparo dos biólogos para atuar junto a órgãos governamentais, mídia, empresas etc.

4. Uso de QSC para embasar estrategicamente intervenções didáticas nas várias disciplinas do curso de Biologia, como casos sobre clonagem ou terapia gênica (SADLER; ZEIDLER, 2004), ou sobre conservação e ética ambiental (BECKERT, 2003). Esses casos podem ser motivadores para a discussão contextualizada de conteúdos do currículo, aliados a conteúdos extracurriculares. 


\section{AGRADECIMENTOS}

D.M.C. agradece aos tutores do curso de extensão Ana Paula Miranda Guimarães, Diego Palmeira, Leonídia Maria Serretti Cruz, Maíra Miele Oliveira Rodrigues de Souza e Uelen Oliveira Moura; à CAPES (PDSE Processo n. BEX 8502/11-0) e à FAPESB (BOL 0197/2009), pela concessão de bolsas de Doutorado, e aos organizadores do Curso de Ecologia do PPGECOBIO-UFBA 2011. N.F.N.N. agradece à FAPESB pela concessão de bolsa de Doutorado, à CAPES (PDSE Processo n. BEX 6084/11-7) e por apoios financeiros para pesquisa. C.N.E.H. agradece ao CNPq por bolsa de produtividade em pesquisa nível 1-B (nº 301259/2010-0) e à FAPESB e ao CNPq por financiamentos de projetos de pesquisa.

\section{REFERÊNCIAS}

BECKERT, C. Dilemas da Ética Ambiental: estudo de um caso. Revista Portuguesa de Filosofia, Filosofia e Ecologia: Elementos para uma Ética Ambiental, n. 59, v. 3, p. 675-687, jul./set. 2003.

BRITO, J. Q. A.; SÁ, L. P. Estratégias promotoras da argumentação sobre questões sóciocientíficas com alunos do ensino médio. Revista Electrónica de Enseñanza de las Ciencias, v.9, n.3, p. $505-529,2010$.

CONRADO, D. M. et al. Construção e validação de ferramenta para investigação das relações entre conhecimento sobre evolução e tomada de decisão socialmente responsável em questões sócio-científicas. VIII Encontro Nacional de Pesquisa em Educação em Ciências, VIII ENPEC, Campinas, p.1-14, 2011.

CONRADO, D. M.; EL-HANI, C. N.; NUNES-NETO, N. F. Sobre a ética ambiental na formação do biólogo. Revista Eletrônica do Mestrado em Educação Ambiental (REMEA), v. 30, n. 1, p. 120-139, jan./ jun. 2013.

COSTA, A. Desenvolver a capacidade de argumentação dos estudantes: um objectivo pedagógico fundamental. Revista Iberoamericana de Educación. n. 46/5, p.1-8, 2008.

DRIVER, R.; NEWTON, P.; OSBORNE, J. Establishing the norms of scientific argumentation in classrooms. Science Education, v. 84, n. 3, p. 287-312, 2000.

ERDURAN, S.; SIMON, S.; OSBORNE, J. TAPping into Argumentation: Developments in the Application of Toulmin's Argument Pattern for Studying Science Discourse. Science Education, v. 88, p. 915-933, 2004.

FELIPE, S. T. Ética e experimentação animal: fundamentos abolicionistas. Florianópolis: EDUFSC, 2007.

HENAO, B. L.; STIPCICH, M. S. Educación en ciencias y argumentación: la perspectiva de Toulmin como posible respuesta a las demandas y desafíos contemporáneos para la enseñanza de las Ciencias Experimentales. Revista Electrónica de Enseñanza de las Ciencias, v. 7, n. 1, p. 47-62, 2008.

JIMÉNEZ-ALEIXANDRE, M. P. A argumentação sobre questões sócio-científicas: processos de construção e justificação do conhecimento na aula. In: Atas do V Encontro Nacional de Pesquisa em Educação em Ciências. V ENPEC, n. 5, Conferência. p. 1-12. 2005. 
JIMÉNEZ-ALEIXANDRE, M. P.; FREDERICO-AGRASO, M. A argumentação sobre questões sociocientíficas: processos de construção e justificação do conhecimento em sala de aula. Educação em Revista, v. 43, p. 13-33, 2006.

JIMÉNEZ-ALEIXANDRE, M. P.; PEREIRO-MUÑOZ, C. Knowledge producers or knowledge consumers? Argumentation and decision making about environmental management. International Journal of Science Education, v. 24, n. 11, p. 1171-1190, 2002.

LACEY, H. A controvérsia sobre os transgênicos: questões científicas e éticas. Aparecida, SP: Idéias \& Letras, 2006. (Filosofia e história da ciência)

LIMA, G. Z. de; LINHARES, R. E. C. Escrever bons problemas. Revista Brasileira de Educação Médica, n. 32, v. 2, p. 197-201, 2008.

LIMA-TAVARES, M.; MORTIMER, E. F.; EL-HANI, C. N. Argumentação em salas de aula de biologia sobre a teoria sintética da evolução. VII Encontro Nacional de Pesquisa em Educação em Ciências, VII ENPEC, 2009.

NASCIMENTO, S.; VIEIRA, R. Contribuições e limites do padrão de argumento de Toulmin aplicado em situações argumentativas de sala de aula de ciências. Revista Brasileira de Pesquisa em Educação em Ciências, v. 8, n. 2, p. 1-20, 2008.

OSBORNE, J. The role of argument in science education. In: BOERSMA, K. et al. (eds.). Research and the Quality of Science Education. Dordrecht: Springer, p.367-380, 2005.

PERELMAN, C. Retóricas. São Paulo: Martins Fontes, 2004.

PERELMAN, C.; OLBRECHTS-TYTECA, L. Tratado da argumentação: A nova retórica. São Paulo: Martins Fontes, 1996.

QUEIROZ, S. L.; SÁ, L. P. O espaço para a argumentação no ensino superior de química. Educación Quimica, v. XX, p. 104-110, 2009.

REGAN, T. Animal rights and environmental ethics. In: BERGANDI, D. (ed.) The Structural Links between Ecology, Evolution and Ethics: The Virtuous Epistemic Circle. Dordrecht: Springer, 2013, p. 117-126 (Boston Studies in the Philosophy and History of Science, v. 296).

SÁ, L. P. Estudo de casos na promoşão da argumentaşão sobre questões sócio-científicas no Ensino Superior de Química. 278p. Tese (Doutorado), Universidade Federal de São Carlos, 2010.

SÁ, L. P.; QUEIROZ, S. L. Argumentação no ensino de ciências: contexto brasileiro. Ensaio, v. 13, n. 2, p.13-30, 2011.

SÁ, L. P.; QUEIROZ, S. L. Promovendo a argumentação no ensino superior de química. Quimica Nova. v. 30, n. 8, p. 2035-2042, 2007.

SADLER, T. D. Moral and ethical dimensions of socioscientific decision-making as integral components of scientific literacy. Association of Science Teachers, Inc. Annual Meeting of the Hoosier Association of Science Teachers, p. 1-17, 2004.

SADLER, T. D.; DONNELLY, L. A. Socioscientific Argumentation: The effects of content knowledge and morality. International Journal of Science Education. v. 28, n. 12, 2006, p. 1463-1488.

SADLER, T. D.; ZEIDLER, D. L. The Morality of Socioscientific Issues: Construal and Resolution of Genetic Engineering Dilemmas. Science Education, n. 88, p. 4-27, 2004.

SALMON, W. C. Lógica. 3.ed. reimp. Rio de Janeiro: LTC, 2010.

SANTOS, W. L. P. dos. Educação CTS e cidadania: confluências e diferenças. Amazônia: Revista de Educação em Ciências e Matemáticas, v. 9, p. 49-62, 2012. 
SANTOS, W. L. P. dos; MORTIMER, E. F. Uma análise de pressupostos teóricos da abordagem C-T-S (Ciência - Tecnologia - Sociedade) no contexto da educação brasileira. Ensaio: Pesquisa em Educação em Ciências, v. 2, p. 1-23, 2002.

SANTOS, W. L. P. dos; MORTIMER, E. F.; SCOTT, P. H. A Argumentação em Discussões Sócio-Científicas: Reflexões a Partir de um Estudo de Caso. Revista Brasileira de Pesquisa em Educação em Ciências, v. 1, n. 1, p. 14-27, 2001.

SARDÀ-JORGE, A.; SANMARTÍ-PUIG, N. Enseñar a argumentar científicamente: un reto de las clases de ciencias. Enseñanza de las Ciencias, v. 18, n. 3, p. 405-422, 2000.

SASSERON, L. H.; CARVALHO, A. M. P. de. Uma análise de referenciais teóricos sobre a estrutura do argumento para estudos de argumentação no ensino de ciências. Revista Ensaio. Belo Horizonte, v. 13, n. 3, p. 243-262, 2011.

SIMONNEAUX, L. Argumentation in Socio-Scientific Contexts. In: ERDURAN, S.; JIMÉNEX-ALEIXANDRE, M. P. (eds.). Argumentation in Science Education: Perspectives from classroom-based research. Dordrecht: Springer, 2007, p.179-199. (Contemporary Trends and Issues in Science Education, v. 35).

SINGER, P. Libertação animal. Porto Alegre: Lugano, 2004.

TOULMIN, S. E. Os usos do argumento. 2. ed. São Paulo: Martins Fontes, 2006.

VELLOSO, A. M. S. et al. Argumentos elaborados sobre o tema "corrosão" por estudantes de um curso superior de química. Revista Electrónica de Enseñanza de las Ciencias, v. 8, n. 2, p. 593-616, 2009.

VELLOSO, A. M. S.; SÁ, L. P.; QUEIROZ, S. L. Casos investigativos no ensino do tópico 'Corrosão'. VI Encontro Nacional de Pesquisa em Educação em Ciências, VI ENPEC, Campinas, p.1-10, 2007.

VON LINSINGEN, I. Perspectiva educacional CTS: aspectos de um campo em consolidação na América Latina. Ciência \& Ensino, v. 1, núm. especial, p. 1-19, 2007.

WESTON, A. A construção do argumento. São Paulo: WMF Martins Fontes, 2009.

ZEIDLER, D. L.; SADLER, T. D.; SIMMONS, M. L.; HOWES, E. V. Beyond STS: a research-based framework for socioscientific issues education. Science Education, v. 89, p. $357-377,2005$.

\section{NOTAS}

${ }^{1}$ Perelman e Olbrechts-Tyteca (1996) entendem argumentos como construções retóricas que buscam mudar a adesão das pessoas a ideias, distinguindo entre argumentos lógicos e retóricos com base na natureza formal e demonstrativa dos primeiros. Para além dos argumentos lógicos, a adesão das pessoas a ideias pode ser modificada por argumentos de outra natureza, os argumentos quase-lógicos, que apelam para a realidade, que estabelecem a realidade, de dissociação de conceitos, para usar a tipologia proposta pelos autores citados. Como argumenta Perelman (2004, p. 49), "ao contrário da demonstração, que se desenvolve em um sistema bem-definido, a argumentação mais frequentemente desenha-se em um corpus de premissas muito maldefinido, e as teses nas quais é baseada podem ser parcialmente compreendidas ou implícitas". O campo da retórica se debruça sobre essa forma mais frequente de argumentação. 
${ }^{2}$ Dada a importância do movimento CTS no Brasil, é conveniente considerar a crítica de Zeidler et al. (2005) à educação CTS, que para eles não estaria, ao menos como tipicamente concebida e praticada, inserida num quadro sociológico ou desenvolvimental coerente, capaz de considerar o desenvolvimento psicológico, epistemológico e do caráter e da virtude do estudante de modo explícito. Eles contrapõem, assim, os objetivos dos currículos CTS, em sua visão aumentar o interesse dos estudantes ao colocar conteúdos científicos dentro de um contexto social, aos objetivos mais amplos da abordagem das QSC, que, mais do que prover um contexto para a aprendizagem de Ciências, busca estimular e promover o desenvolvimento intelectual do estudante no que tange à sua moralidade e ética, bem como à compreensão da interdependência entre ciência e sociedade. A crítica feita por estes autores ao movimento CTS, bem como a contraposição com as QSC, não parece aplicar-se a vários desenvolvimentos do primeiro no contexto brasileiro, no qual muitas propostas não se limitam a prover contexto para a aprendizagem de Ciências, mas se ocupam de dimensões não somente éticas e morais, mas também sociopolíticas das relações CTS(A), com ênfase, inclusive, sobre a natureza de tais relações no Brasil e na América Latina (ver, e.g., VON LINSINGEN, 2007; SANTOS; MORTIMER, 2002; SANTOS, 2012).

${ }^{3}$ Apesar de haver uma estudante de Veterinária, solicitamos a todos que assumissem o papel social de biólogo, como planejado na elaboração da QSC.

${ }^{4}$ Para suscitar reflexões sobre o caso, adotamos uma perspectiva senciocêntrica (SINGER, 2004) da ética animal, em vez de, por exemplo, uma perspectiva reganiana, que se baseia na ideia de que animais não humanos são também sujeitos-de-uma-vida (REGAN, 2013). Para usos posteriores desse caso, poderiam ser adotadas questões que contemplem outros segmentos da ética animal.

${ }^{5} \mathrm{O}$ questionário completo apresenta questões de avaliação do curso em todos os seus aspectos. No presente trabalho, apresentamos apenas a questão referente à aprendizagem da argumentação, que também foi usada na interpretação dos resultados obtidos no estudo.

${ }^{6}$ Sobre esse modelo, consideramos apenas dois dos vários elementos que a autora utiliza para avaliar a qualidade da argumentação em QSCs, por considerarmos que eram mais relevantes para os objetivos deste trabalho. Para mais detalhes sobre esse modelo, consultar Sá; Queiroz (2011) e Sá (2010).

${ }^{7} \mathrm{Na}$ perspectiva bem-estarista da ética animal, não há reconhecimento de deveres morais diretos de seres humanos para com animais, mas apenas reconhecimento de deveres negativos (regidos pelo princípio da não maleficência), o que resulta em ações que visam não causar sofrimento aos animais (FELIPE, 2007).

${ }^{8}$ Avaliamos o aspecto predominante nos elementos do argumento (dado, garantia, conclusão etc.).

${ }^{9}$ Aqui, podemos fazer uma analogia com o caso de determinadas companhias produtoras de alimentos que defendem alimentos transgênicos. Dificilmente, tais companhias se posicionariam contra os transgênicos, que são sempre defendidos como meios legítimos de produzir grande quantidade de alimentos, inclusive como meio de superar o problema do abastecimento mundial (LACEY, 2006). É a esse tipo de enviesamento ideológico a que nos referimos, sendo o mesmo com frequência também encontrado nos grandes veículos de comunicação em massa.

Recebido: 31/10/2013

Aprovado: 18/11/2014 
Contato:

Universidade Federal da Bahia Instituto de Biologia Departamento de Biologia Geral Laboratório de Ensino, Filosofia e História da Biologia (LEFHBIO) Campus Universitário de Ondina Rua Barão do Geremoabo, 147 Ondina Salvador $|\mathrm{BA}|$ Brasil CEP 40.170-290 
